\title{
A Conversão dos Negócios Jurídicos: seu interesse teórico e prático.
}

Antônio Junqueira de Azevedo

Professor Assistente - Doutor da Faculdade de Direito da Universidade de São Paulo.

CONVERSAOO DO NEGÓCIO JURIDICO: NOÇÃO, FUNDAMENTO E ESPECIES.

Conversão do negócio jurídico (conversão substancial) é o ato pelo qual a lei ou o juiz consideram um negócio, que é nulo, anulável ou ineficaz, como sendo de tipo diferente do efetivamente realizado, a fim de que, através desse artifício, ele seja considerado válido e possam se produzir pelo menos alguns dos efeitos manifestados pelas partes como queridos. Podemos dar como exemplo de conversão, um caso que, embora conhecido na jurisprudência e na doutrina brasileira, jamais vem qualificado como de conversão (em virtude da pouca ou nenhuma atenção que esse instituto tem merecido de nossos juristas); queremos nos referir ao endosso de título já vencido, o qual não vale como endosso, e sim, como cessão de crédito; o que há, nessa hipótese, é a conversão do endosso em cessão de crédito ${ }^{1}$. O $\S 2 .^{\circ}$, do art. $8 .^{\circ}$, do Decreto n. ${ }^{\circ}$ 2.044, de 1908, diz: "O endosso posterior ao vencimento da letra tem o efeito de cessão civil”; o endosso é, pois, nulo; entretanto, a fim de que

1. "O efeito do endôsso dado após o vencimento da letra de câmbio, como da nota promissória, está expresso no art. 8.० § 2.0, Lei n.o 2.044 , de 1908 , é o da cessão civil. Donde se segue que o cedido, devedor, pode opor ao cessionário a mesma defesa que teria contra o cedente". (TASP, 5. Câm. Civ. ap. civ. 86.475, Tanabí; rel. Min. MEDEIROS JR.; j. 23-12-66; maioria de votos). "O endôsso póstumo da cambial equivale à cessão civil; em consequência, admissiveis contra o cessionário todas as exceções que o devedor poderia opor ao cedente" (TASP, 4. 'Câm. Civ.; ap. civ. 89.995, SP; 
nem tudo se perca, é ele convertido em cessão civil. $\mathrm{O}$ ato realizado não terá, assim, os efeitos cambiários (abstração, autonomia, responsabilidade solidária do endossante etc.), mas haverá transferência do crédito, do endossante-cedente, para o endossatário-cessionário; portanto, pelo menos alguns dos efeitos desejados pelas partes, graças a essa mudança de tipo, se produzirão.

A conversão, em sentido próprio, é, pois, esse fenômeno pelo qual um negócio, que, dentro do tipo em que foi concebido, é nulo ou anulável ou ineficaz, vale, por um artifício da lei ou do intérprete, como negócio de tipo diverso.

A conversão obedece a uma orientação comum a diversos institutos da teoria das nulidades em geral, isto é, ao princípio da conservação, pelo qual, sempre que possível, devem o legislador e o juiz evitar que deixem de se produzir os efeitos de um negócio realizado; é esse princípio que explica, por exemplo, que, diante de uma cláusula nula, se possa considerar inválida somente essa cláusula, e não o negócio todo (art. 153, ro. Código Civil, — nulidade parcial - utile per inutile non vitiatur), ou que, diante de um negócio viciado, a lei não o considere inválido, e sim, espere que o interessado peça a anulação (art. 152, do Código Civil, anulabilidade), ou ainda que, em hipóteses, como as de vício redibitório e eviç̧ão parcial, a lei não imponha, sem mais, a ineficácia, mas admita que o interessado possa promover uma "correção" do negócio, a fim de que este continue a produzir efeitos (arts. 1105 e 1114, do Código Civil). Nota-se em todos esses casos, a mesma idéia orientadora a que também obedece a conversão, isto é, a de conservar, sempre que possível, os efeitos manifestados como queridos pelas partes ${ }^{2}$

rel. design. Min. BATALHA DE CAMARGO; j. 18-04-67; maioria de votos). "A nota promissória endossada após o vencimento é cobrável por ação executiva, devendo ser feita prova da posterioridade do endôsso, que tem então o efeito de cessão civil, ampliando-se a defesa nessa conformi-

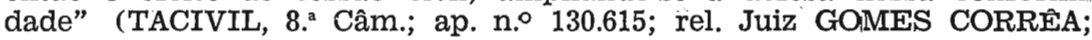
j. 05-11-69; V.u.).

2. Para o princípio da conservação, vejam-se, conforme já indicamos em tese a ser publicada, os seguintes autores: TRABUCCHI, Istituzioni di diritto civile, 15. ${ }^{a}$ ed., Padova, Cedan, 1966, pág. 196; CARIOTA FERRARA, Il negozio giuridico nel diritto privato italiano, Napoli, Morano, s.d., pág. 394; CRISCUOLI, La nullità parziale del negozio giuridico, Milano, Giuffré, 1959. pág. 103; SANTORO PASSARELLT, Dottrina generali del diritto civite, 9. ed., Napoli, Jovene, 1966, pág. 147 e pág. 233; BETTI, Teoria generali del negozio giuridico, $3 .^{2}$ ed., in Trattato di diritto civile italiano, Torino, UTET, 1960, pág. 363. 
A noção dada de inicio sobre a conversão corresponde ao sentido próprio da palavra; diz respeito à conversão substancial, que implica mudança de tipo do negócio. Trata-se, aí, de fenômeno de alteração da qualificação categorial do negócio ${ }^{3}$; as partes realizam um negócio de tipo $X$ e, como, dentro dessa categoria $X$, esse negócio é nulo, anulável ou ineficaz, a lei ou o juiz determinam uma alteração da qualificação categorial, de forma que o negócio, considerado dentro da categoria $Y$, possa produzir pelo menos alguns dos efeitos que as partes queriam. Há, porém, além dessa espécie de conversão, a chamada conversão formal, que não implica alteração de tipo, e sim, somente uma mudança da forma originariamente utilizada; o negócio continua o mesmo, mas a forma passa o ser outra, cujos requisitos são menos severos. O exemplo clássico se encontra no Digesto e consiste no caso do soldado, que, podendo testar através do chamado testamentum militis (que valia qualquer que fosse sua forma), decidiu, porém, testar segundo o direito comum; ora, havendo morrido sem que tivesse completado o testamento pela forma ordinária, mas já tendo se manifestado, de um modo que seria válido como testamento militar, à pergunta sobre se não se poderia considerar o que já havia sido feito como testamento militar, respondeu Ulpiano que $\operatorname{sim}^{4}$. Deu-se, pois, no caso, uma mudança da forma do negócio, sem que houvesse alteração de categoria. No direito moderno, pode-se exemplificar a conversão formal com um contrato que não exija escritura pública (promessa de compra e venda, por exemplo), mas, para cuja realização, as partes, visando maior segurança, escolham essa forma; ora, se, posteriormente, se verificar que a escritura pública é nula, porque quem a lavrou não tinha fé pública, ainda assim o negócio valerá como se tivesse sido

3. Cf. BETTI (pág. 506, op. cit., nota 2) que diz que se trata de fenômeno de correção da qualificação jurídica do negócio ou de algum elemento seu.

4. DIGESTO (ULPIANUS, lib 2, ad Sabinum), 29.1.3: "Si miles, qui destinaverat communi iure testari, ante defecerit, quam testaretur, Pomponius dubitat. Sed cur non in milite diversum probet? neque enim, qui voluit iure communi testari, statim beneficio militari renuntiavit, nec credendus est quisquam genus testandi eligere ad impugnanda sua iudicia, sed magis utroque genere voluisse propter fortuitos casus, quemadmodum plerique pagani solent, cum testamenti faciunt perscripturam adiicere velle hoc etiam vice codicillorum valere, nec quisquam dixerit, si imperfectum sit testamentum, codicillos non esse; nam secundum nostram sententiam etiam Divus Marcus rescripsit". 
feito por instrumento particular ${ }^{5}$ Vemos, que, na conversão formal, há uma alteração da forma documental escolhida ${ }^{6}$

Além dessa classificação (conversão substancial e formal) pode ainda a conversão (atendendo-se a quem a realiza) ser classificada em legal ou judicial, conforme ela seja feita pela lei ou pelo juiz. Exemplo de conversão legal temos no Capítulo I, do Título "Dos contratos", em que nosso Código Civil, ao tratar da formação dos contratos, no art. 1.083, cenverte a aceitação (feita fora de prazo, ou com adições, restriçóes ou modificações) em proposta. Exemplo de conversão judicial, temos no caso de novação subjetiva (com mudança do devedor), feita quando o devedor já está em mora, em que, sendo a novação nula, poderá o juiz fazê-la valer como renúncia do credor às vantagens para ele advindas da mora 7 .

Dados esses esclarecimentos elementares sobre a noção, o fundamento e as espécies da conversão, passaremos a tratar, em dois itens sucessivos, do interesse teórico e do interesse prático que a conversão sem dúvida possui.

Infelizmente, cumpre lembrar que, no Brasil, o instituto tem sido negligenciado seja na doutrina, seja na jurisprudência; a primeira parece não ter percebido sua enorme importância teórica para a concepção do negócio jurídico e a segunda não se deu conta de que poderá ser ele um instrumento eficaz para obter soluções equânimes, em inúmeros casos, em que a rigorosa aplicação dos preceitos sobre as nulidades pode conduzir à injustiça.

A omissão do direito brasileiro, a respeito da conversão, se explica pelo fato de não ter o Código Civil trazido um preceito expresso referente a ela. Entretanto, mesmo assim, embora explicável, não nos parece justificável esse silêncio, de vez que, participantes que somos, em matéria jurídica, da família romano-germânica, não só há diversos Códigos irmãos que trazem preceito sobre ela ( $\S 140$, do BGB; art. 1424, do Código Civil italiano; art. 293. ${ }^{\circ}$, do Código Civil português) como também, mesmo naqueles países, em que a legislação não traz preceito expresso

5. Cf. VIEIRA NETO, Ineficácia e Convalidação do Ato Jurídico, São Paulo, Max Limonad, s. d., pág. 144.

6. Cf. CASTRO Y BRAVO, El Negocio Jurídico, Madrid, Instituto Nacional de Estudios Jurídicos, 1967, pág. 487.

7. Exemplo de BETTI, pág. 510, op. cit., nota 2. 
(Espanha; Itália, na vigência do Código Civil de 1.865; Portugal, na vigência do Código de 1867 ; etc.), o assunto não é descurado. Em todos esses países, há monografias versando exclusivamente sobre a conversão ${ }^{8}$.

O Anteprojeto de Código das Obrigações, do prof. Caio Mário da Silva Pereira, no art. 68, previu a conversão, mas, de maneira extremamente restritiva (porque limitada aos negócios nulos por defeito de forma); ocorreu o mesmo no Projeto que se lhe seguiu (art. 70, no Projeto de Código das Obrigações, de 1965).

O Anteprojeto de Código Civil, de 1972, a regulou em seu art. 172 e acompanhou, em sua formulação, o que consta do $\S 140$, do BGB, e do art. 1424, do Código Civil italiano. O mesmo artigo foi repetido ipsis litteris, sob número 171, na publicação da revisão do mesmo Anteprojeto (Anteprojeto de Código Civil, de 1974). Eis o seu teor: "Se, porém, o negócio jurídico nulo contiver os requisitos de outro, subsistirá este quando o fim, a que visavam as partes, permitir supor que o teriam querido, se houvessem previsto a nulidade"

\section{O INTERESSE TEÓRICO DA CONVERSÃO.}

O grande interesse teórico da conversão está, a nosso ver, no fato de ela se prestar admiravelmente bem para facilitar a revisão, que a concepção do negócio jurídico, como ato de vontade, deve sofrer.

8. Vide: LUIGI MOSCO, La conversione del negózio giuridico, Napoli, Eugenio Jovene, 1947; JOSÉ LUIZ DE LOS MOZOS, La Conversión del Negocio Jurídico, Barcelona, Bosch c 1959; BETTI, Conversione. In: NOVISSIMO Digesto' Italiano, Torino, UTET, s. d., vol. 4; RAUL JORGE RODRIGUES VENTURA, A conversão dos Atos Jurídicos no Direito Romano, Lisboa, Imprensa Portuguesa, 1947. Acreditamos que, na literatura jurídica brasileira, a mais antiga referência à conversão esteja em ANTONIO JOAQUIM RIBAS, Curso de Direito Civil, 3. ${ }^{a}$ ed., Rio de Janeiro, Rodrigues, 1905, pág. 448. Não há, no nosso direito, nenhuma monografia sobre o assunto; há somente referências em obras mais amplas; assim: no Tratado de Direito Privado, de PONTES DE MIRANDA (onde há todo um capítulo, o IV, no volume IV), no Código Civil Interpretado, de CARVALHO SANTOS (com. ao art. 130) e no Manual PAULO DE LACERDA (Vol. III, parte $1^{a}$ ) em parte a cargo de EDUARDO ESPINOLA (págs. 93 e 558). Também: VIEIRA NETO, págs. 143 e seguintes, n. 31 , op. cit., nota 5. A única decisão jurisprudencial, em que vimos referência à conversão, no direito brasileiro, se encontra à Revista dos Tribunais, vol. 327 , pág. 244 , em acórdão relatado pelo desembargador Vieira Neto. 
A "concepção voluntarista" do negócio é, até hoje, prevalecente na doutrina. Indubitavelmente dominante entre os nossos autores, essa concepção envolve uma perspectiva psicológica do negócio, que não condiz com a índole social do direito. Antes que manifestação da vontade individual (Clóviș), manifestação lícita de vontade (João Franzen de Lima), ato de vontade (Washington de Barros Monteiro) ou ato de vontade visando a um fim (Sílvio Rodrigues), o negócio deve ser considerado como aquilo que a sociedade vê como sendo o ato de vontade de alguém. A perspectiva, através da qual o negócio jurídico deve ser encarado, passa a ser uma perspectiva social, e não, individual.

O negócio não é, no nosso modo de entender, propriamente o ato de vontade de alguém, mas sim, o que a sociedade vê como sendo o ato da vontade de alguém.

Essa aparente sutileza (que reduz, mas não elimina, o papel da vontade no negócio) tem graves consequências práticas; limitamo-nos, para não fugir demais ao nosso tema, a lembrar o que se passa em matéria de interpretação do negócio. Mudando a perspectiva, como queremos, o intérprete não deverá se preocupar com o fôro íntimo do agente, com a sua intenção, com aquilo que ele quis e não manifestou; deverá, antes, atender às circunstâncias que rodeiam o negócio e que socialmente lhe fixam os contornos, isto é, com aquilo que aos outros, parece ser o que o agente queria.

Dentro dessa orientação, contrária ao dogma da vontade, a conversão, tomada como objeto de reflexão, apresenta grande riqueza; seja como conversão judicial, seja como conversão legal, se examinada sem preconceito, ela consubstancia um caso de negócio jurídico que, de fato, não foi querido pelas partes; ela coloca, assim, em xeque toda a concepção do negócio como ato de vontade. Na conversão legal, é a lei que quer o negócio que a final produz efeitos: a oferta jamais foi querida como oferta por quem manifestou sua aceitação. Na conversão judicial, por sua vez é o juiz que atribui ao negócio efeitos de outro negócio que as partes efetivamente não realizaram; ele deixa de lado a qualificação categorial que as partes deram ao ato que praticaram. Assim, se as partes realizaram, depois que o devedor originário já estava em mora, uma novação subjetiva (com simples mudança do devedor) e se essa novação, que é 
ato plurilateral, visando extinguir a obrigação antiga e criar uma obrigação nova, for nula, o juiz poderá aproveitá-la como ato unilateral do credor, pelo qual este renuncia às consequências da mora; desta forma, o juiz, mantendo a obrigação antiga, permitirá ao devedor originário extingui-la sem maiores ônus, pelo pagamento.

Passando a examinar mais demoradamente a conversão judicial, que oferece maior interesse teórico, detenhamo-nos um pouco sobre os termos em que está redigido o supra transcrito art. 171, do Anteprojeto de Código Civil, de 1974 (termos que, como dissemos, não diferem dos do $\S 140$, do BGB, e dos do art. 1424, do Código Civil italiano). O artigo, prevendo a hipótese de conversão judicial, foi redigido sob evidente preconceito voluntarista; realmente, como a conversão implica que o negócio convertido (isto é, o negócio que surge da conversão) não tenha sido querido pelas partes, já que se deve pressupor que o negócio por elas realizado (e, portanto, o negócio de fato querido) seja nulo ou anulável ou ineficaz, os autores voluntaristas procuram justificar essa situação, por uma ilógica "vontade presumida das partes" $\mathrm{O}$ artigo em pauta diz que, se o negócio realizado for nulo e se ele tiver os requisitos de outro, o juiz poderá deixar subsistir este outro, quando o fim, a que visavam as partes, permitir supor que o teriam querido, se houvessem previsto a nulidade.

Ora, parece-nos, em primeiro lugar, que somente um preconceito teórico poderia criar a necessidade de imaginar uma vontade presumida; a final, que vem a ser uma vontade presumida ? essa vontade que o juiz presume, essa vontade por ele suposta, será, de fato, vontade das partes ? Pensamos que não; vontade presumida não é vontade (e esta frase, sem elipse, significa: vontade de alguém, presumida por outrem, não é vontade de alguém) Segue-se daí que o recurso à "vontade presumida" parece-nos, no mínimo, inútil.

Em segundo lugar, o intérprete, para aplicar o preceito em causa, terá que partir de uma base hipotética que foge ao bom-senso. Ele terá, para realizar a conversão, que supor que as partes quereriam o novo negócio, se houvessem previsto a nulidade do primeiro. Ora, isto, de acordo com o que comumente acontece, encerra um absurdo; se as partes houvessem previsto a nulidade do primeiro negócio, a lógica das coisas 
impõe a conclusão de que elas procurariam, antes de mais nada, evitar essa nulidade. Não há razão para a priori supor que, havendo previsto a nulidade, elas deixassem de realizar o negócio que realizaram, para realizarem negócio diverso. Portanto, o preceito obriga o juiz a raciocinar em bases falsas, o que, além de inútil, é inconveniente.

O dogma da vontade, que, no fim do século passado, já influenciara o $\S 140$, do BGB, continuou a se impor, disgraziatamente ${ }^{9}$, no art. 1424 , do Código Civil italiano, de 1942, e, agora, também entrou no art. 171, do nosso mais atual Anteprojeto de Código Civil. Apesar disso, como diz Betti, o intérprete deverá se encaminhar para uma solução objetiva da conversão, isto é, deverá realizá-la, desde que se possa entender que o novo negócio esteja compreendido no que foi efetivamente declarado (e, portanto, independentemente dessa entidade mítica, que é a "vontade presumida" das partes)

Acreditamos que o supra citado artigo do Anteprojeto (e, diga-se entre parentesis, o Anteprojeto, em outros pontos, seguiu, antes, a teoria da declaração, Erklarungstheorie, que a da vontade, Willenstheorie), poderia ser assim redigido: "Se um negócio jurídico inválido ou ineficaz contiver todos os requisitos de outro, subsistirá este, quando o fim, que dele resulta, permitir supor não ser ele contrário à vontade das partes, tal e qual foi declarada"

Como se percebe, não há, aí, necessidade de imaginar qual teria sido a vontade das partes, se houvessem previsto a nulidade ou a ineficácia; basta que o fim, que resulta do novo negócio, não seja contrário ao que as partes declararam querer. A questão, assim, parece-nos que encontra solução que não despreza a vontade das partes, mas há de se tratar da vontade declarada, e não de uma vontade qualquer, interna ou hipotética. Essa solução combina, com maior equilibrio, e salvo melhor juízo, objetivismo e subjetivismo.

\section{O INTERESSE PRÁTICO DA CONVERSÃO.}

Finalizando o presente artigo, passaremos a lembrar diversos casos em que se verifica o fenômeno da conversão.

9. Cf. BETTI, pág. 508, op. cit., nota 2. 
São casos de conversão legal ${ }^{10}$, além do já citado (da aceitação convertida em oferta — art. 1083, do Código Civil), mais os seguintes: o reconhecimento de filho incestuoso ou adulterino (este, durante a vigência da sociedade conjugal), que é nulo como reconhecimento, mas que, de acordo com o art. 405, vale para os efeitos de prestação de alimentos ${ }^{11}$; a instituição de fideicomisso, em que, sendo nula a indicação do fiduciário, é convertida em substituição vulgar ${ }^{12}$; a compra-e-venda com pacto de retrovenda, quando se trata de negócio simulado, a qual, se nos termos do art. $1^{\circ}$ do Decreto-lei n. ${ }^{\circ} 2.689$, de 1940 , é nula, mas o respectivo instrumento vale "como prova do mútuo, deixando assegurado ao suposto vendedor o direito de pleitear o reajuste compulsório como proprietário de imóvel e ao suposto comprador a preferência que compete ao credor hipotecário" (isto é, a compra-e-venda com pacto de retrovenda se converte em mútuo com garantia hipotecária; há conversão, embora o caso esteja relacionado com a simulação) No Anteprojeto de Código Civil, do professor Orlando Gomes, previu-se também a conversão da instituição de fideicomisso em constituição de usufruto 13 No Código Civil italiano (art. 1059, $2^{\circ}$ ), a concessão de servidão, feita exclusivamente por um condômino e que, assim, não é eficaz para constituir o direito real, vale, porém, como acordo que cria para o condômino a obrigação de não se opor ao exercício de um direito pessoal por aquele que seria o adquirente da servidão ${ }^{14}$

São casos de conversão judicial: o de cambial nula valendo como promessa de pagamento ${ }^{15}$; o de contrato de fornecimento (somministrazione), que, feito pelo pai, sem ordem judicial, sobre fundo de comércio

10. Inúmeros autores não consideram a conversão legal como espécie de conversão própria; a nosso ver, porém, não têm razão. As diferenças entre a criação e a aplicação do direito, entre as atividades do legislador e do juiz, são somente de grau (vide KELSEN, Teoria Pura do Direito, trad. JOÃO BAPTISTA MACHADO, 2. ${ }^{a}$ ed., Coimbra, Américo Amado, vol. II, págs. 85 e seguintes).

11. Cf. também o art. $254,2 .^{\text {" }}$ do Código Civil Italiano.

12. Cf. art. 1740, do Código Civil e TRABUCCHI, pág. 917, op. cit, nota 2.

13. Cf. ORLANDO GOMES, Memória Justificativa do Anteprojeto de Reforma do Código Civil, Departamento de Imprensa Nacional, 1963, pág. 115 e $\S$ único, do art. 805, do Projeto de Código Civil, de 1964.

14. Cf. BETTI, pág. 511, op. cit. nota 2.

15. Este caso é, no direito italiano, de conversão legal (Cf. art. 2..$^{\circ}$ do R. D., de 14 de dezembro de 1933 e art. 1988 , do Código Civil italiano). 
do filho, e que, assim, deveria ser totalmente ineficaz por ultrapassar os limites da administração ordinária, é convertido, para as coisas já entregues, em compra-e-venda de bens móveis ${ }^{16}$; o de mútuo, em que não houve a tradição, convertido em promessa de mútuo, ou em contrato de abertura de crédito ${ }^{17}$; a renúncia antecipada da prescrição, que, não valendo como renúncia (art. 161, do Código Civil), é convertida em interrupção da prescrição ${ }^{18}$; o testamento nulo, convertido em codicilo ${ }^{19}$; a falsa declaração de paternidade e maternidade, a qual, constituindo até mesmo crime (segundo o art. 242, do Código Penal), é convertida em legitimação adotiva; etc. ${ }^{20}$.

16. Exemplo de MOSCO, op. cit., nota 8.

17 Vide BARASSI, Istituzioni di diritto civile, 4. ${ }^{a}$ ed., Giuffrè, Milano, 1955, pág. 454.

18. Vide SERPA LOPES, Curso de Direito Civil, vol. I, pág. 397.

19. Vide R.T. $327 / 240$.

20. Como se percebe, nem todos os casos, em que a conversão pode ser aplicada, são de nulidade propriamente dita; poderá haver casos de anulabilidade ou de ineficácia em sentido restrito, que também justifiquem a conversão. Por isso, pensamos que a expressão "se o negócio jurídico nulo", que consta do art. 171, do Anteprojeto de Código Civil, de 1974, deveria ser substituída por outra; em nossa sugestão para a redação do artigo em causa, escrevemos "se o negócio jurídico inválido ou ineficaz", que é expressão mais ampla e abrange as várias hipóteses. 